Supporting Information

\title{
Cerium(III) Complex Modified Gold Electrode: An Efficient Electrocatalyst for the Oxygen Evolution Reaction
}

Samiran Garain, ${ }^{\dagger}$ Koushik Barman,${ }^{\ddagger}$ Tridib Kumar Sinha, ${ }^{\perp}$ Sk Jasimuddin, ${ }^{*}{ }^{\ddagger}$ Jörg Haeberle, ${ }^{\S}$

Karsten Henkel, ${ }^{\S}$ Dieter Schmeisser, ${ }^{\S}$ and Dipankar Mandal ${ }^{*}, \dagger$

${ }^{\dagger}$ Organic Nano-Piezoelectric Device Laboratory, Department of Physics Jadavpur University Kolkata 700032, India

${ }^{\ddagger}$ Department of Chemistry, Assam University, Silchar-788011, India

${ }^{\perp}$ Materials Science Centre, Indian Institute of Technology (IIT), Kharagpur 721302, India

${ }^{\S}$ Brandenburgische Technische Universität Cottbus-Senftenberg, Angewandte Physik-Sensorik, K.-Wachsmann-Allee 17, 03046 Cottbus, Germany.

*Corresponding Authors

Dr. Dipankar Mandal

E-mail:dipankar@phys.jdvu.ac.in

Dr. Sk. Jasimuddin

E-mail: j.seikh@gmail.com 


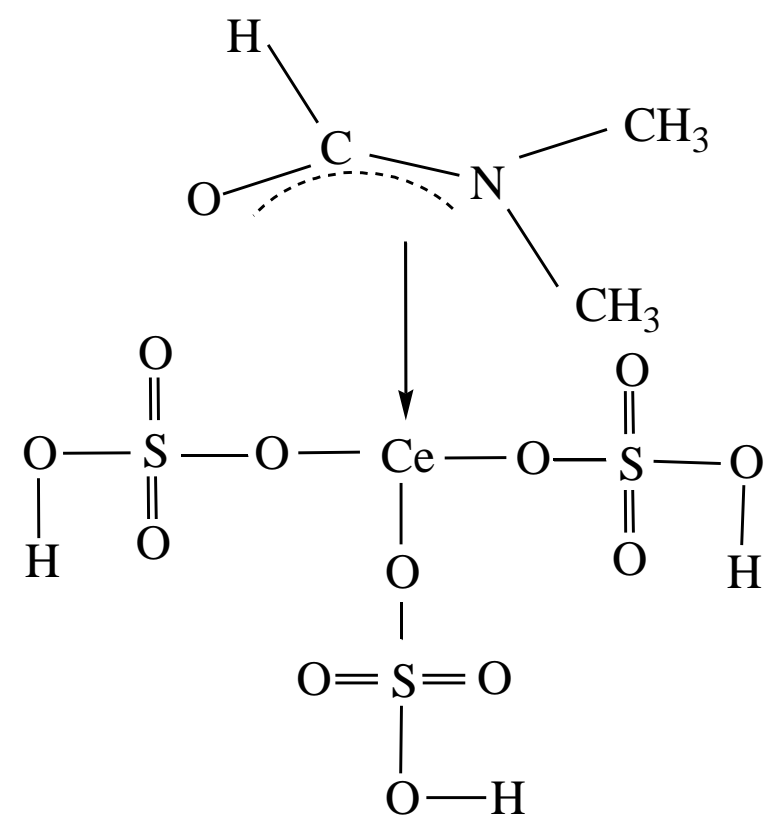

Figure S1. Structure of the $\left[\mathrm{Ce}{ }^{\mathrm{III}}(\mathrm{DMF})\left(\mathrm{HSO}_{4}\right)_{3}\right]$ complex.
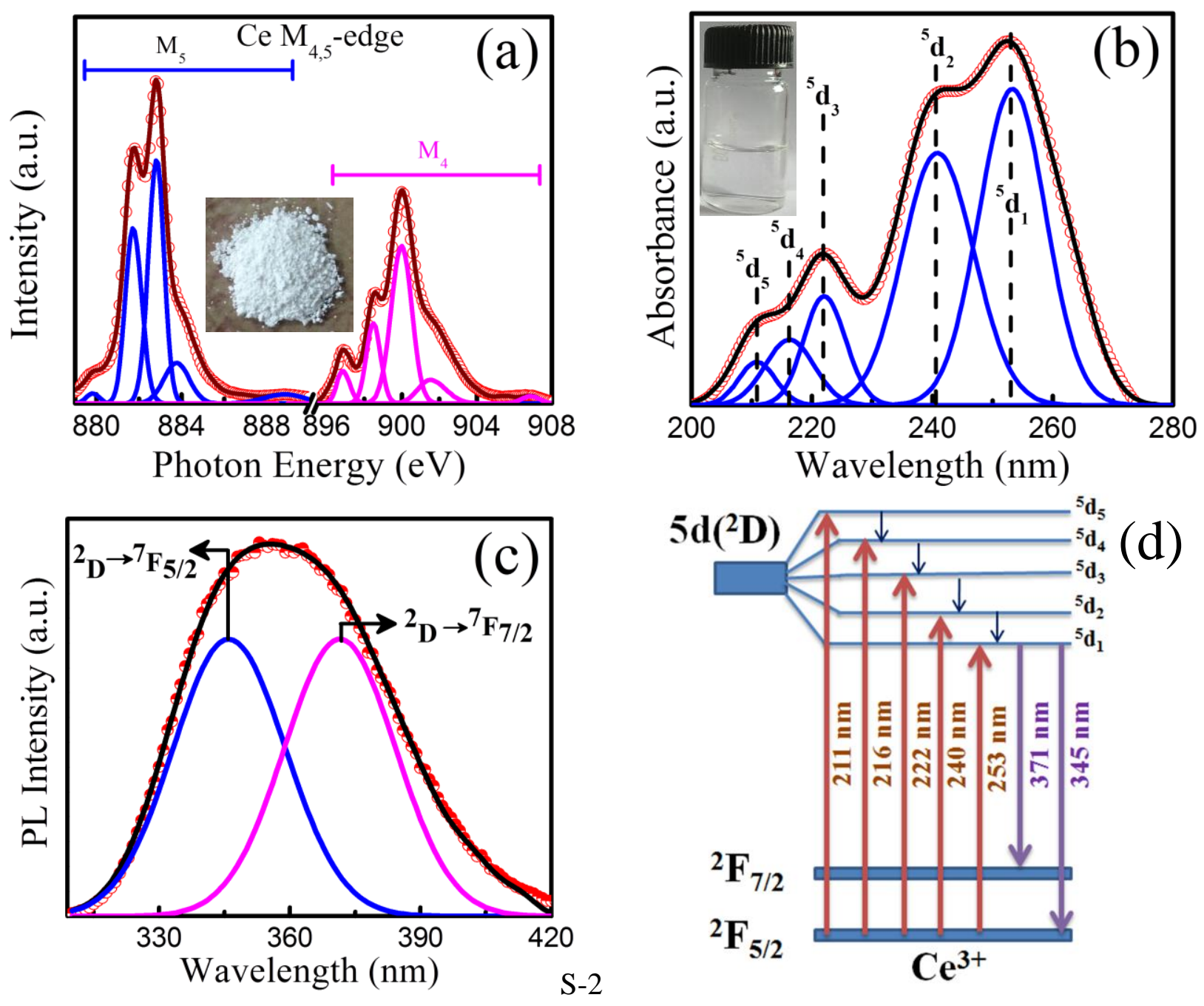
Figure S2. (a) Ce $\mathrm{M}_{4,5}$-edge XAS spectra of Ce $\mathrm{C}^{\mathrm{III}}$-complex powder. (b) UV-vis absorbance spectrum showing the transition from ${ }^{2} \mathrm{~F}_{2}$ to corresponding $5 \mathrm{~d}$ splitting levels and (c) photoluminescence (PL) spectrum $\left(\lambda_{\mathrm{ex}}=250 \mathrm{~nm}\right)$ of the aqueous solution of the $\left[\mathrm{Ce}^{\mathrm{III}}(\mathrm{DMF})\left(\mathrm{HSO}_{4}\right)_{3}\right]$. (d) Electronic energy-level diagram explaining the excitation and light emission from the $\mathrm{Ce}^{3+}$ center of the $\mathrm{Ce}(\mathrm{III})$-complex. The insets in panel $\mathrm{a}$ and $\mathrm{b}$ show the corresponding photographs of the $\mathrm{Ce}(\mathrm{III})$-complex powder and the transparent aqueous solution respectively.

\section{S1.1 X-ray absorption spectroscopy}

X-ray absorption spectroscopy (XAS) provides clear information about the valence state of cerium. The excited electrons from $3 \mathrm{~d}$ core orbitals directly probe the valence $4 \mathrm{f}$-orbitals. XAS at the Ce3d-edge delivers an opportunity to uniquely evaluate the f-electron occupancy and electronic structure in the $\mathrm{Ce}^{3+}$ compounds. ${ }^{\mathrm{S}-\mathrm{S} 3}$ The XAS spectra originate from electric-dipoleallowed transitions from Ce 3d-orbitals to unoccupied states that contain some degree of $4 \mathrm{f}$ character, e.g., the $3 \mathrm{~d}^{10} 4 \mathrm{f}^{\mathrm{n}} 5 \mathrm{~d}^{0} \rightarrow 3 \mathrm{~d}^{9} 4 \mathrm{f}^{\mathrm{n}+1} 5 \mathrm{~d}^{0}$ transitions. ${ }^{\mathrm{S} 2, \mathrm{~S} 3}$ The spectra features are separated into two groups corresponding to the $3 \mathrm{~d}_{3 / 2} \rightarrow 3 \mathrm{~d}_{5 / 2}$ spin-orbit splitting. The individual groups show considerable structures which are due to the coupling of the spin and orbit moments of the 3d and $4 \mathrm{f}$ electrons. ${ }^{\mathrm{S} 1}$ The spectra must be described by intermediate coupling and hence the designations $3 \mathrm{~d}_{3 / 2}\left(\mathrm{M}_{4}\right)$ and $3 \mathrm{~d}_{5 / 2}\left(\mathrm{M}_{5}\right)$-edges correspond to the spin-orbit coupling of the $3 \mathrm{~d}^{9}$ core-hole (Figure S2a). 


\section{S1.2 X-ray photoelectron spectroscopy (XPS) $\dagger \dagger$}

i† XPS was performed by an instrument equipped with a $\mathrm{Mg} \mathrm{K \alpha}$ X-ray source and a hemispherical electron analyzer made by Leybold-Heraeus.
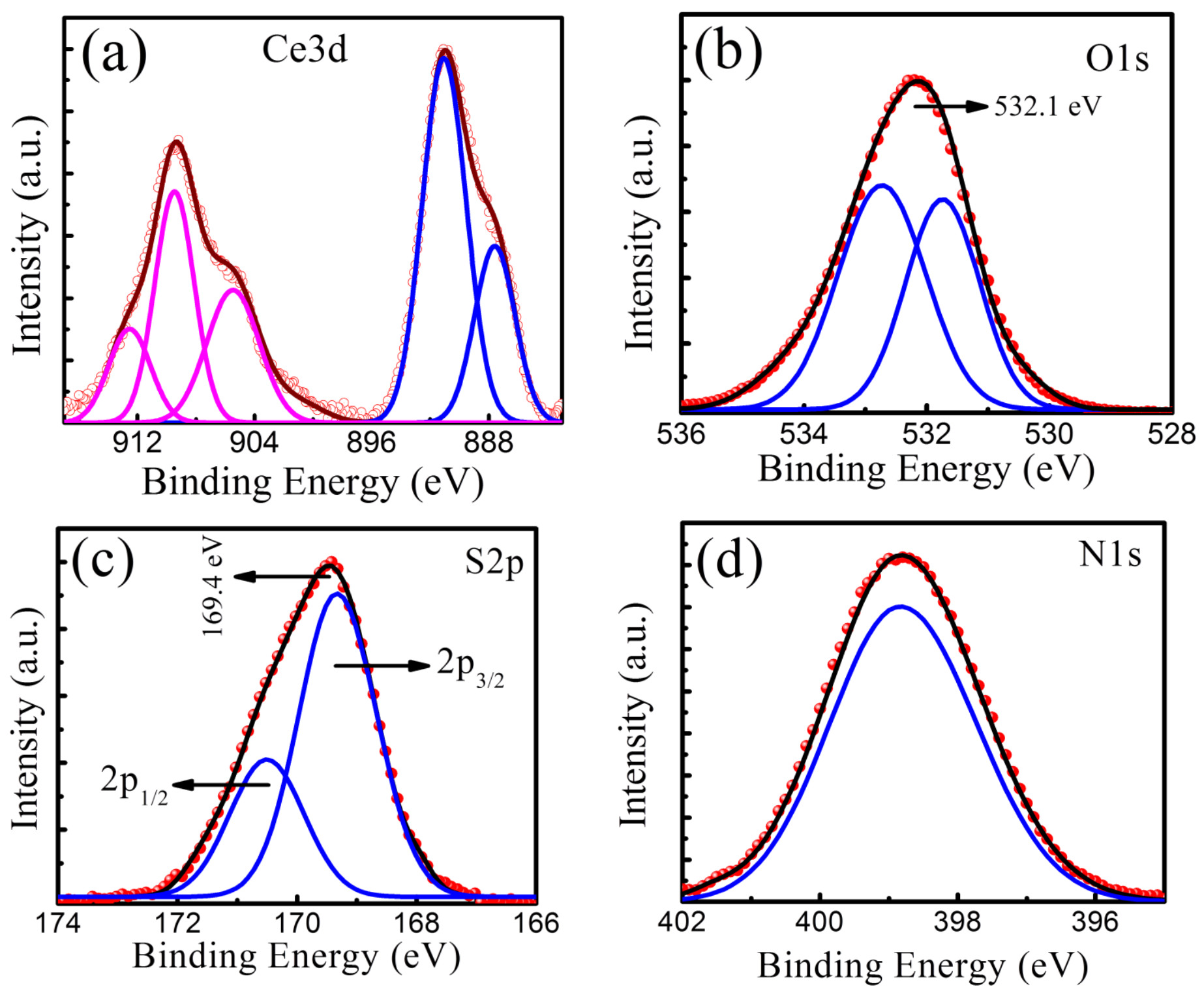

Figure S3. XPS core level spectra of the $\left[\mathrm{Ce} \mathrm{eII}^{\mathrm{III}}(\mathrm{DMF})\left(\mathrm{HSO}_{4}\right)_{3}\right]$ complex: (a) Ce3d, (b) O 1s, (c) $\mathrm{S} 2 \mathrm{p}$, and (d) N 1s. 


\section{S1.3 UV-vis absorption spectroscopy}

$\mathrm{Ce}^{3+}$ ions have only one electron in their $4 \mathrm{f}$ shell, which can be excited to the $5 \mathrm{~d}$ orbitals upon UV irradiation $\left(4 \mathrm{f}^{1} 5 \mathrm{~d}^{0} \rightarrow 4 \mathrm{f}^{0} 5 \mathrm{~d}^{1}\right)$. In the $4 \mathrm{f}$ configuration of the free ion two levels exist namely the ${ }^{2} \mathrm{~F}_{5 / 2}$ and ${ }^{2} \mathrm{~F}_{7 / 2}$ states, while in the $5 \mathrm{~d}$ configuration five components $\left({ }^{2} \mathrm{D}\right.$ splitting levels) are present, shown in Figure S2d. It is noteworthy that the absorption peaks attributed to the $f \rightarrow d$ electron transitions of $\mathrm{Ce}^{3+}$ can be observed in the wavelength region of 200 to $280 \mathrm{~nm}$.

\section{S1.4 Characterization of modified gold electrode surface}

It is known that L-cysteine has an isoelectric point of 5.06 and carries a negative charge in the $\mathrm{pH}$ domain of 6.0-7.5. At the $\mathrm{pH}$ of 7.0, the interaction between the Ce(III)-complex and Lcysteine reaches a maximum as observed in the cathodic peak current because the complex is carrying positive surface charges resulting in a strong electrostatic interaction with the lone pair of the $\mathrm{NH}_{2}$ groups of the L-cysteine. At lower $\mathrm{pH}$ values (5.0-6.5), a relatively weak response was obtained due to the poor interaction between the carboxyl group of the L-cysteine and the $\mathrm{Ce}(\mathrm{III})$-complex. In the higher $\mathrm{pH}$ range (7.5-10.0) the free amino group may interact with the gold surface resulting in a weaker interaction between the amino group and the Ce(III)-complex and consequently in lower $\mathrm{I}_{\mathrm{pc}}$.

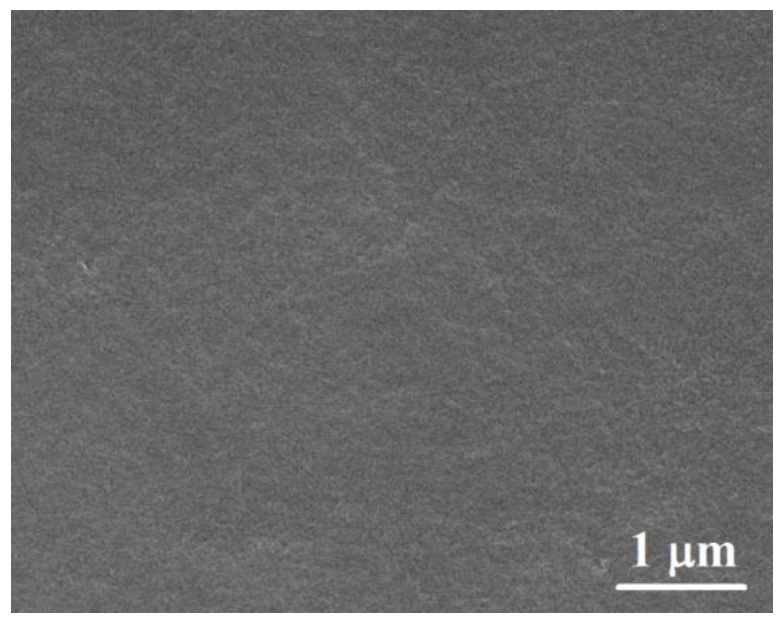

Figure S4 SEM image of the bare gold electrode. 


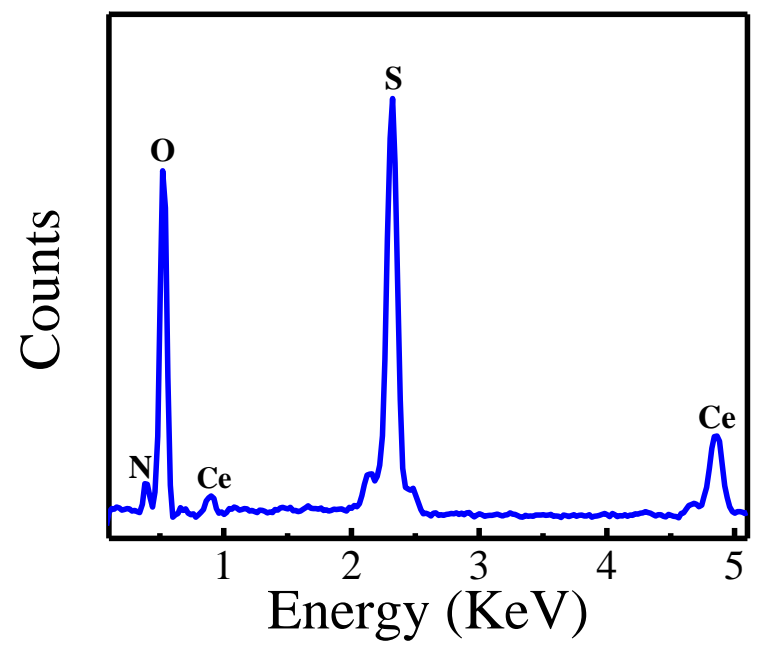

Figure S5. EDAX spectrum of $\left[\mathrm{Ce}(\mathrm{DMF})\left(\mathrm{HSO}_{4}\right)_{3}\right]$-L-cycteine-Au electrode.
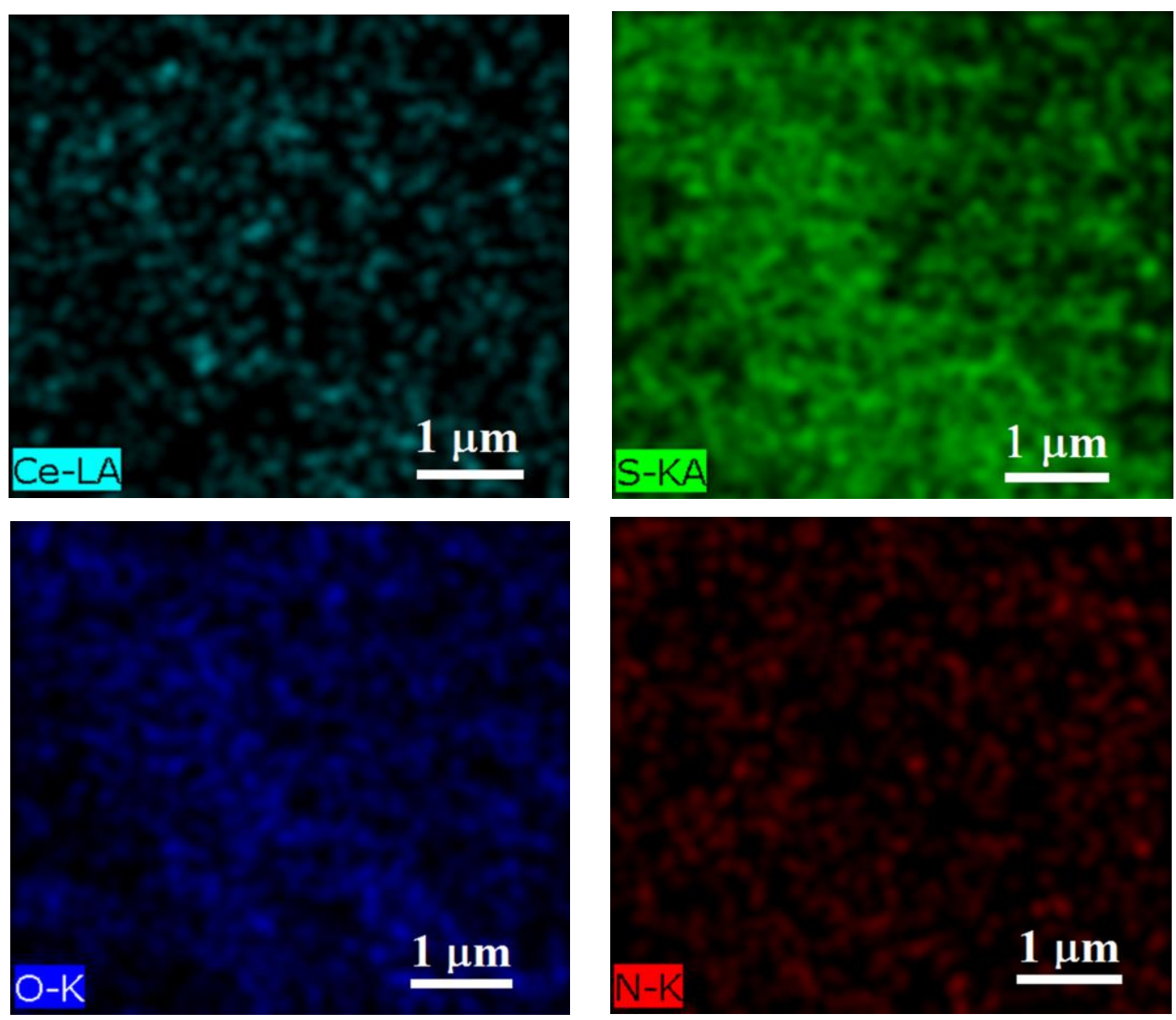

Figure S6. Elemental mapping images of cerium, sulphur, oxygen and nitrogen as labeled corresponding to the SEM image of the $\left[\mathrm{Ce}(\mathrm{DMF})\left(\mathrm{HSO}_{4}\right)_{3}\right]-\mathrm{L}$-cycteine-Au electrode. 

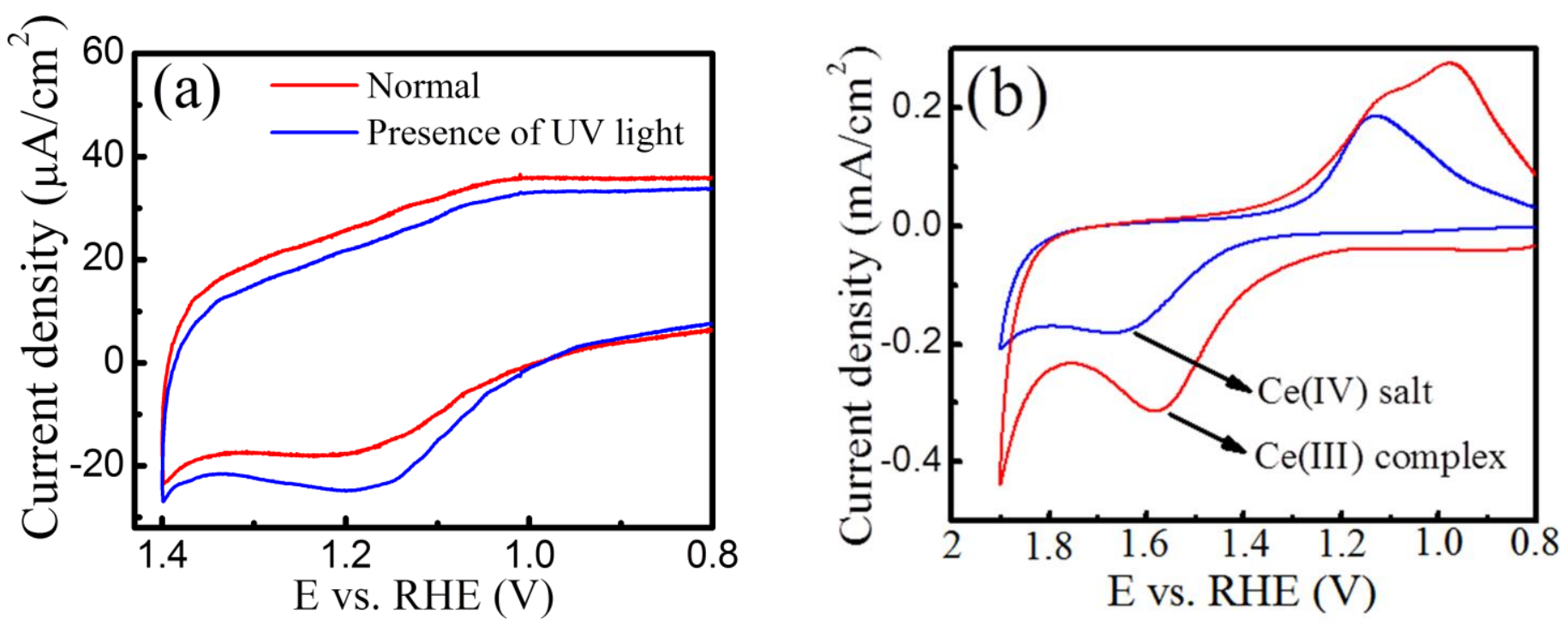

Figure S7. CV of the (a) Ce-(III)-complex modified L-cysteine-Au electrode in 0.1 M PBS solution (scan rate: $100 \mathrm{mV} \mathrm{s}^{-1}, \mathrm{pH}$ 7.0) with (blue) and without (red) UV irradiation (the anodic peak indicates the oxidation of $\left[\mathrm{Ce}^{\mathrm{III}}\right]$ to $\left[\mathrm{Ce}^{\mathrm{IV}}\right]$ ), and (b) $\mathrm{Ce}(\mathrm{III})$-complex-L-cystine modified (red) and Ce(IV)-L-cysteine modified (blue) gold electrodes in 0.1 M PBS solution at pH 7.0 (the anodic peak indicates the oxidation of water).
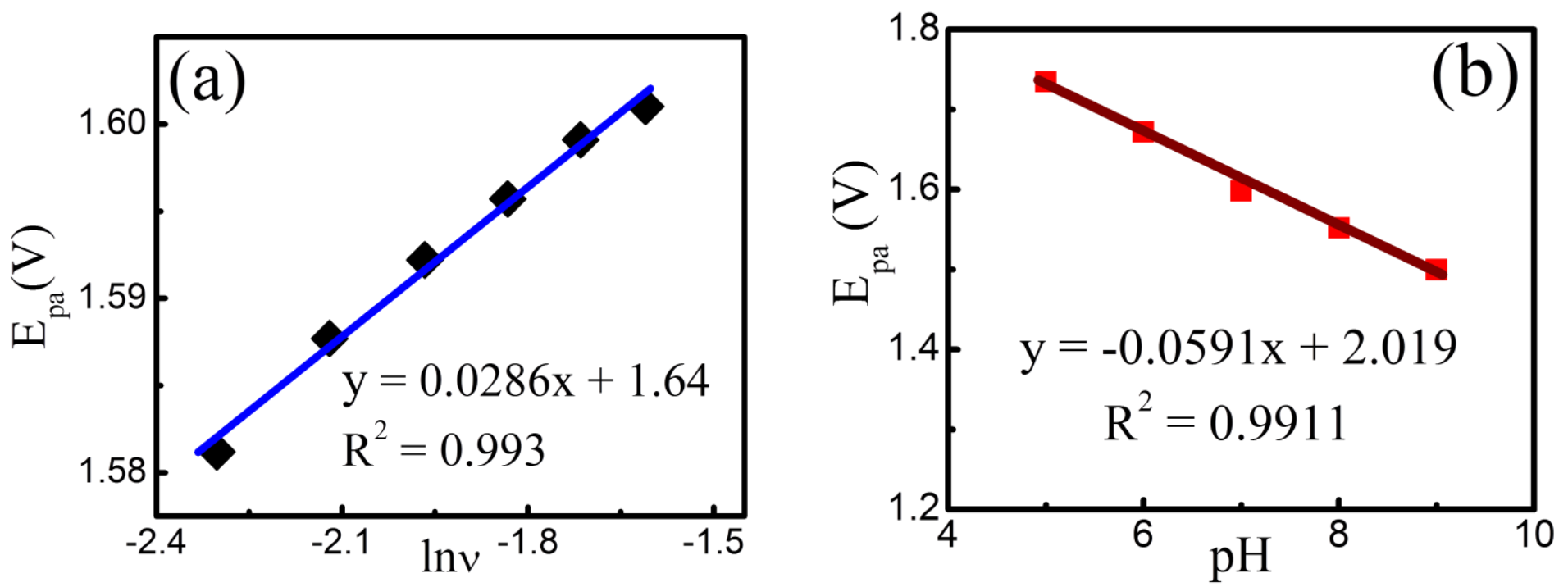

Figure S8. Plot of (a) the anodic peak potential ( $\left.\mathrm{E}_{\mathrm{pa}}\right)$ vs. $\ln v$ and (b) anodic peak potential $\left(\mathrm{E}_{\mathrm{pa}}\right)$ vs. $\mathrm{pH}$ values of the solution. 

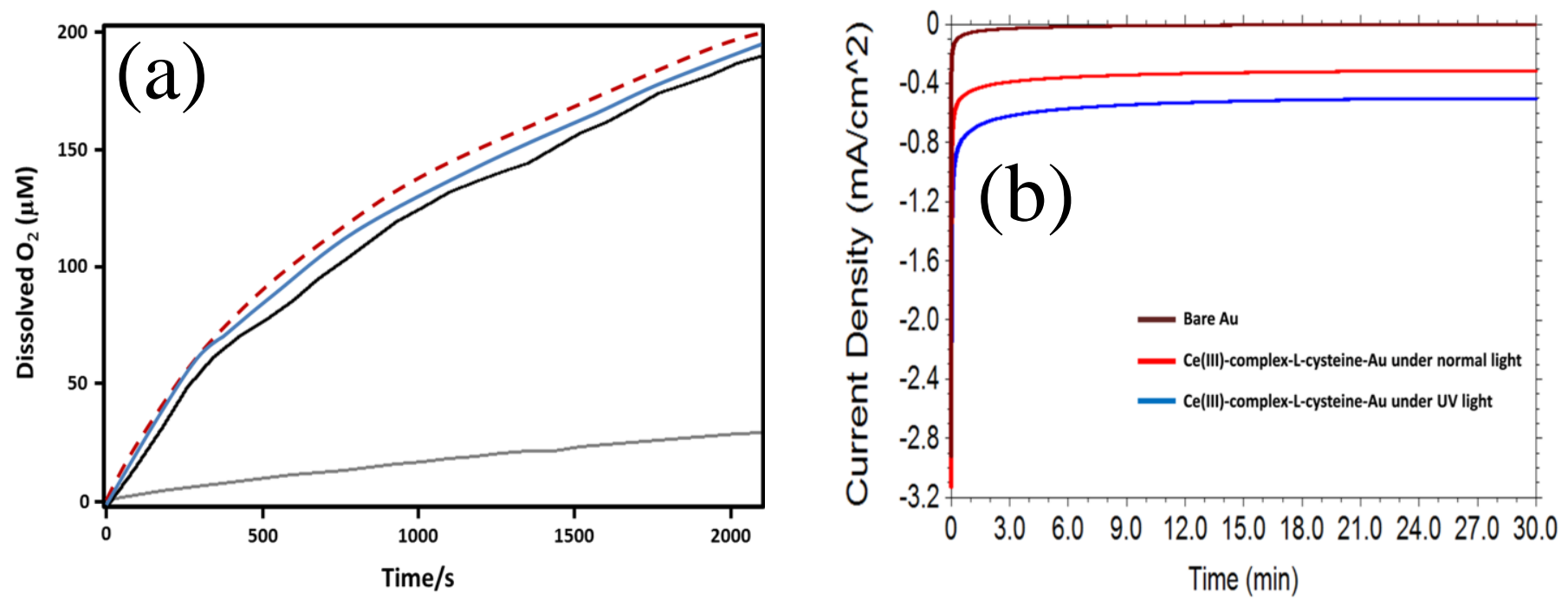

Figure S9. (a) The $\mathrm{O}_{2}$ evolution during the bulk electrolysis of water in a gas tight electrochemical cell in $\mathrm{N}_{2}$ atmosphere (PBS buffer, $\mathrm{pH} 7.0$ ) with (black curve) and without (gray curve) the catalyst $(1 \mathrm{mM})$, as measured with a fluorescence probe. The dotted line shows the theoretical oxygen evolution with $100 \%$ efficiency and the blue curve is obtained in the presence of UV-light and catalyst (b) Bulk electrolysis with (red curve) and without (brown curve) the Ce(III)-complex catalyst $(1 \mathrm{mM})$ at an Au electrode in $0.1 \mathrm{M}$ PBS solution $(\mathrm{pH} 7.0)$ at $1.58 \mathrm{~V}$ vs. RHE. The blue curve is measured with the catalyst under UV irradiation.

\section{S1.5 Cyclic Voltammogram in the presence of $\mathbf{N}_{2}$ and acetate buffer solution}

There is a sufficient evidence for the oxidation of water and the reduction of generated $\mathrm{O}_{2}$ via indirect pathway. The following experiments were done for confirmation. 1. At first, the potential was swept negatively in the absence of $\mathrm{O}_{2}\left(\mathrm{~N}_{2}\right.$ atm. $)$. Consequently, no peak was observed for the $\mathrm{O}_{2}$ reduction ('a' to ' $\mathrm{b}$ ' in Figure $\mathrm{S} 10(\mathrm{a})$ ). 2. Then, the potential was swept positively (' $b$ ' to ' $d$ ') and then negatively (' $d$ ' to ' $g$ ').In the latter case, the peaks labeled with 'e' and ' $\mathrm{f}$ ' were observed due to the reduction of $\mathrm{O}_{2}$ which was generated before (' $b$ ' to 'd') as visible by the peak labeled with 'c' (Figure S10(a)). Also, we 
have used acetate buffer solution (Figure S10(b)) and got similar result like for the PBS solution confirming that the peak at $1.58 \mathrm{~V}$ corresponds only to the water oxidation reaction.
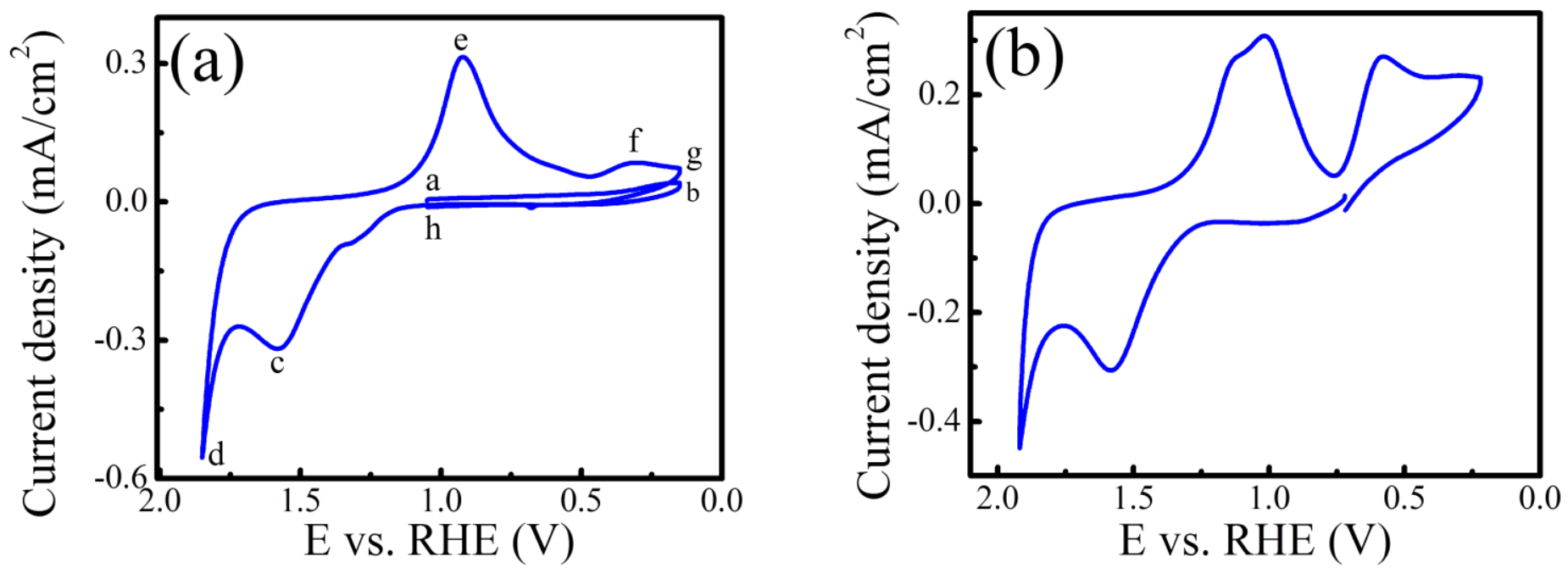

Figure S10. CV of the Ce(III)-complex-L-cysteine modified gold electrode (a) in absence of $\mathrm{O}_{2}$ $\left(\mathrm{N}_{2}\right.$ atmosphere, scan rate: $100 \mathrm{mV} \mathrm{s}^{-1}, \mathrm{pH}$ 7) and (b) in presence of acetate buffer solution (scan rate: $\left.100 \mathrm{mV} \mathrm{s}^{-1}, \mathrm{pH} 7\right)$.
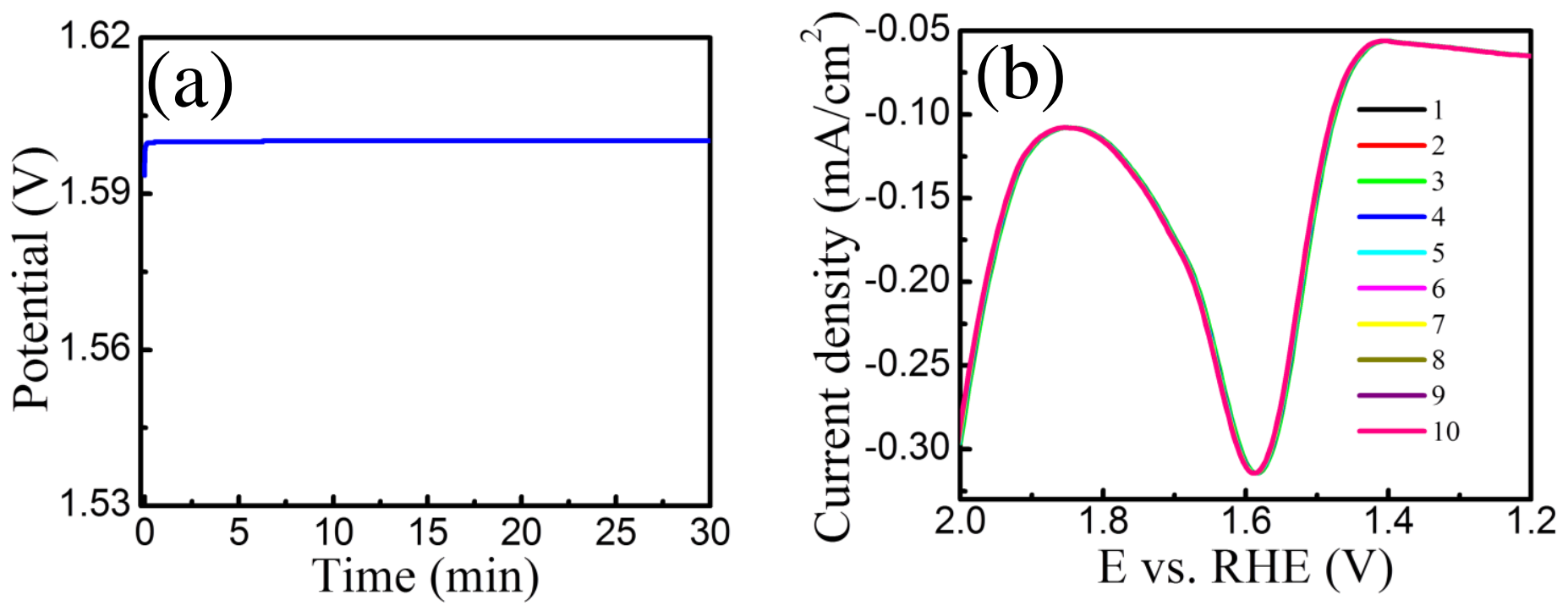

Figure S11. (a) Chronopotentiograms in 0.1 M PBS (pH 7.0) at the Ce(III)-complex-L-cysteineAu electrode at $0.32 \mathrm{~mA} / \mathrm{cm}^{2}$. (b) Repetitive LSV in 0.1 M PBS (pH 7.0) at the Ce(III)-complexL-cysteine-Au electrode. 
Table S1. Data for long term stability measurement performed with intervals of 10 days.

\begin{tabular}{|c|c|c|c|c|}
\hline Days & $\begin{array}{l}\text { Current density } \\
\quad\left(\mathrm{mA} / \mathrm{cm}^{2}\right)\end{array}$ & $\begin{array}{c}\text { Relative } \\
\text { standard } \\
\text { deviation } \\
\text { (RSD) } \\
(\%)\end{array}$ & $\begin{array}{l}\text { Potential (V) } \\
\text { vs. RHE }\end{array}$ & $\begin{array}{c}\text { Relative } \\
\text { standard } \\
\text { deviation } \\
(\mathrm{RSD})(\%)\end{array}$ \\
\hline 0 & 0.31607 & & 1.585 & \\
\hline 10 & 0.31607 & 0.03 & 1.585 & 0.09 \\
\hline 20 & 0.31601 & & 1.587 & \\
\hline 30 & 0.31584 & & 1.588 & \\
\hline
\end{tabular}

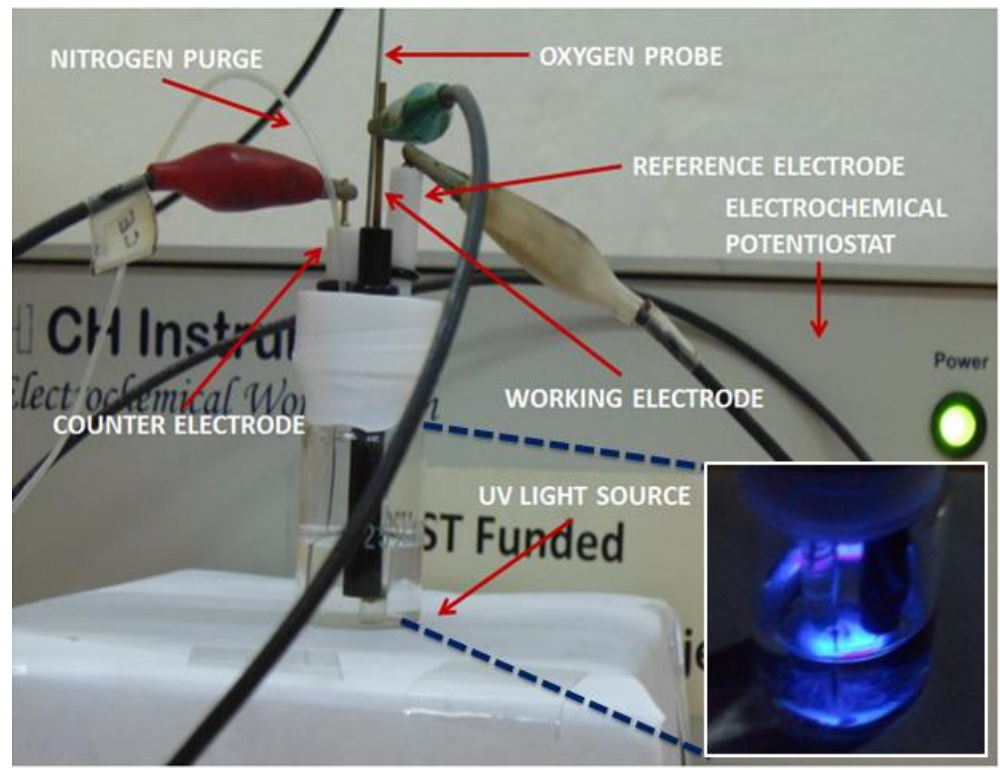

Figure S12. Experimental setup for the oxidation of water in normal condition and under the irradiation of UV light (inset). 


\section{S1.6 Experimental Setup for Electrochemistry}

The electrochemical and photo-electrochemical experiments were carried out under normal day light and UV light source $(365 \mathrm{~nm})$, respectively, in a gas-tight electrochemical cell containing 0.1 M phosphate buffer solution $(\mathrm{pH}=7.0)$. The UV-light source is kept inside a box and the UV-light was allowed to pass through a pinhole. During photo-electrochemical experiments the electrochemical cell was placed over the pinhole of the box and turn on the UV-light as shown in the photograph (Figure S12). A three electrode system was used in the measurement where $\mathrm{Ce}(\mathrm{III})$-complex-L-cysteine-Au served as the working electrode, $\mathrm{Ag} / \mathrm{AgCl}(3.0 \mathrm{M} \mathrm{KCl})$ as the reference electrode and Pt wire was used as the counter electrode. All experiments were performed at ambient temperature and inert atmosphere.

The measured potential versus $\mathrm{Ag} / \mathrm{AgCl}$ was converted to the reversible hydrogen electrode (RHE) scale according to the Nernst equation

$\mathrm{E}_{\mathrm{RHE}}=\mathrm{E}_{\mathrm{Ag} / \mathrm{AgCl}}+0.059 \mathrm{pH}+\mathrm{E}_{\mathrm{Ag} / \mathrm{AgCl}}^{\mathrm{o}}$

where $\mathrm{E}_{\mathrm{RHE}}$ is the potential versus $\mathrm{RHE}, \mathrm{E}_{\mathrm{Ag} / \mathrm{AgCl}}$ is the experimentally measured potential against $\mathrm{Ag} / \mathrm{AgCl}$ reference and $\mathrm{E}_{\mathrm{Ag} / \mathrm{AgCl}}^{\mathrm{o}}=0.210$ at $25^{\circ} \mathrm{C}$.

\section{REFERENCES}

S1. Beche, E.; Charvin, P.; Perarnau, D.; Abanades, S. Flamant, G. Ce 3d XPS Investigation of Cerium Oxides and Mixed Cerium Oxide (CexTiyOz). Surf. Interface Anal. 2008, 40, $264-267$.

S2. Bugaris, D. E.; Copping, R.; Tyliszczak, T.; Shuh, D. K.; Ibers, J. A. $\mathrm{La}_{2} \mathrm{U}_{2} \mathrm{Se}_{9}$ : An Ordered Lanthanide/Actinide Chalcogenide with a Novel Structure Type. Inorg. Chem. 2010, 49, 25682575 . 
S3. Kaindl, G.; Brewer, W. D.; Kalkowski, G.; Holtzberg, F. M-Edge X-Ray Absorption Spectroscopy: A New Tool for Dilute Mixed-Valent Materials. Phys. Rev. Lett. 1983, 51, 20562059.

Video S1- Oxygen bubbles formation on the Ce(III)-complex modified electrode. 